\section{LOS MUSEOS, OFERTA CONSOLIDADA PARA EL TURISMO SOSTENIBLE Y LA CALIDAD DEL PAISAJE}

\author{
Manuel Antonio Zárate Martín \\ Universidad Nacional de Educación a Distancia \\ ORCID iD: http://orcid.org/0000-0003-3709-7814 \\ mzarate@geo.uned.es \\ Alejandro García Ferrero \\ Universidad Nacional de Educación a Distancia \\ ORCID iD: http://orcid.org/0000-0001-6565-5591 \\ alejandro.garcia@bec.uned.es
}

Cómo citar este artículo/Citation: Zárate Martín, M. A. y García Ferrero, A. (2017). Los museos, oferta consolidada para el turismo sostenible y la calidad del paisaje. Arbor, 193 (785): a401. doi: http://dx.doi.org/10.3989/arbor.2017.785n3007

Recibido: 18 septiembre 2016. Aceptado: 30 mayo 2017.

RESUMEN: El Consejo Internacional de Museos (ICOM) y la Federación Mundial de Amigos de los Museos (WFFM) reconocen los museos como oferta de turismo cultural sostenible para una sociedad cada vez con más tiempo libre y capacidad de desplazarse por ocio y turismo. En este artículo se analiza la evolución de los museos desde su primera función de acopio de materiales para su conservación hasta la situación actual, en la que forman parte de la oferta turística y compiten para aumentar sus visitantes, potenciando sentimientos de identidad colectiva y de respeto y tolerancia hacia otras culturas, de acuerdo con la Carta del Turismo Sostenible de Lanzarote de 1995. Los museos contribuyen también a través del turismo a la generación de empleo y a la puesta en valor del paisaje siguiendo estrategias de la Convención del Paisaje Europeo de 2000.

PALABRAS CLAVE: Turismo sostenible; cultura museística; visitantes; generación de empleo y riqueza; valor del paisaje.

\section{MUSEUMS, A CONSOLIDATED OFFER FOR SUSTAINABLE TOURISM AND THE QUALITY OF THE LANDSCAPE}

Copyright: (c) 2017 CSIC. Este es un artículo de acceso abierto distribuido bajo los términos de la licencia Creative Commons Attribution (CC BY) España 3.0.

ABSTRACT: The International Council of Museums (ICOM) and the World Federation of Friends of Museums (WFFM) for worldwide Sustainable Cultural Tourism acknowledge that museums constitute an example of sustainable cultural tourism for a society with increasing free time and the ability to move for reasons of leisure and tourism. This paper analyzes the evolution of museums since their initial function of gathering material for its conservation to the current situation, in which museums form part of the tourism offer and compete among themselves to increase the number of visitors, and enhance feelings of a collective identity and of respect and tolerance towards other cultures in accordance with the Charter for Sustainable Tourism of 1995. Museums also contribute, through tourism, to generating employment and enhancing the landscape following strategies of the Convention of the European landscape of 2000.

KEYWORDS: Sustainable tourism; museum culture; visitors; generating employment and wealth; enhancing the landscape. 


\section{INTRODUCCIÓN. TODOS SOMOS TURISTAS EN LOS MUSEOS}

En una sociedad cada vez con más tiempo libre para ocio y formación personal y con posibilidades crecientes de movilidad por los avances tecnológicos, el turismo es una de las principales oportunidades para satisfacer el deseo de descubrir lugares, compartir inquietudes con otras gentes, conocer modos de vida, intercambiar experiencias, observar formas de producción y disfrutar de la visita de museos y de toda clase de eventos culturales. Todo esto, que repercute en la organización del territorio, obliga a ampliar el concepto del turismo, dejando obsoletas definiciones basadas solo en criterios de desplazamiento y tiempo, como la de la Organización Mundial del Turismo (OMT), aprobada en Otawa, en junio de 1991: "turismo es el conjunto de actividades que realizan las personas durante sus viajes y estancias en lugares distintos al de su entorno habitual, por un periodo de tiempo consecutivo inferior a un año, con fines de ocio, por negocios y otros motivos". Así, se precisa como umbral para un desplazamiento turístico pasar más de veinticuatro horas fuera del domicilio habitual. Son los criterios presentes en todas las estadísticas de turismo, entre ellas las del Instituto Nacional de Estadística de España (INE); sin embargo, la práctica permite calificar de turismo desplazamientos de menos de veinticuatro horas que, incluso, no suponen pernoctar fuera del lugar de residencia. $Y$ en sentido inverso, hay desplazamientos de más de veinticuatro horas fuera del hogar que no merecen ser calificados como turismo.

Cada vez más se tiende a fundamentar el turismo en el acceso a la alteridad, a lo distinto y no cotidiano, pero que satisface la curiosidad, el afán de descubrir, conocer y aprender, también dentro de los lugares de residencia habitual. Sin olvidar la definición tradicional, el concepto de turismo se amplía y da respuestas a las dificultades para diferenciar quiénes son turistas y quiénes no, y cuándo una forma de consumo es turística y cuándo no lo es. Así, proliferan las ofertas guiadas para visitas insólitas que no distinguen entre foráneos y residentes (Vergopoulos, 2013), dentro del denominado turismo de exploración urbana (Garrett, 2012), que incluye el "exotismo de lo próximo" (Michel, 2012), el redescubrimiento de los barrios marginales y degradados o de los barrios multiculturales (Rath, 2007).

Algunos ejemplos de esta naturaleza son las rutas turísticas guiadas y gratuitas del ayuntamiento de Toledo (http://www.toledo-turismo.com/es/rutas-guiadas-gra- tuitas_1626), el programa de turismo accesible Madrid para todas y todos (https://www.esmadrid.com/programa-turismo-accesible-madrid-todas-todos) o el de Barcelona (http://www.48hopenhousebarcelona.org/). En general, son propuestas orientadas a revalorizar lo local y a convertir a cualquier persona en turista en su propia "casa". Evidentemente, la visita a museos participa de estas prácticas como oferta turística que no distingue entre residentes y foráneos y que nos pone ante visitantes de distinta procedencia que comparten motivaciones, características sociales y comportamientos.

Los museos forman parte actualmente de todo proyecto recreativo y de ocupación del tiempo libre relacionado con el turismo (Equipe M.I.T, 2002). El Consejo Internacional de Museos (ICOM) y la Federación Mundial de Amigos de los Museos para el Turismo Cultural Sostenible (WFFM), en su declaración de 2007, los reconocen también como oferta de turismo cultural sostenible y señalan la variedad de elementos a los que afectan: turistas, población local, lugares arqueológicos y paisajes. Tal como se recoge en la Propuesta para una Carta de Principios para los Museos y el Turismo Cultural, formulada por el ICOM en la conferencia de Bolivia y Perú del año 2000: "los agentes turísticos y autoridades, y los museos animan la participación activa de las comunidades locales en la planificación tanto de la gestión del patrimonio como del funcionamiento de los lugares turísticos y la acción recíproca entre los visitantes, en un marco de respeto hacia los valores y la hospitalidad que se les ofrecen". Por eso, los museos representan una aportación para el turismo sostenible y para toda la población, para los residentes y los visitantes, tanto desde los puntos de vista educativo y cultural como económico y político. De ese modo, los museos contribuyen a alcanzar objetivos de formación personal como los propuestos por la UNESCO para 2005-2014, la década de la Educación para el Desarrollo Sostenible.

Por otro lado, los museos favorecen la sostenibilidad turística al reducir la estacionalidad e impulsar la ocupación hotelera a lo largo del año. Con ello se responde también a las demandas sociales de entretenimiento por aumento del tiempo libre y de nueva distribución del tiempo reglado de descanso a través de los distintos meses del año. Así, 'descanso' no coincide con 'inactividad', como ocurre frecuentemente con el turismo de sol y playa. A la vez, las visitas de museos y otras actividades culturales ocupan cada vez más el tiempo de los individuos y un lugar destacado en las motivaciones de los desplazamientos y el empleo del tiempo libre. Es significativo que el $60,7 \%$ de los es- 
pañoles realicen alguna actividad cultural cuando se desplazan fuera de su localidad, cifra que asciende al $65,3 \%$ si el viaje es por ocio, recreo o vacaciones. En el caso de los turistas internacionales, el 56\% realiza alguna actividad cultural en su estancia en España, según el Anuario de Estadísticas Culturales de 2015, del Ministerio de Cultura.

A lo anterior se añade que la visita de museos es uno de los principales componentes del turismo cultural. Los museos atraen por sus fondos, pero también por sus exposiciones temporales y la arquitectura de sus edificios, casi siempre en construcciones de valor patrimonial. Así mismo, proliferan recientemente los museos en las ciudades de tamaño medio y pequeño e incluso en medios rurales, contemplados por las administraciones públicas como parte de sus estrategias para el desarrollo local.

Por último, en un marco en el que aumentan las personas que utilizan sus vacaciones para cambiar de actividad fuera de su residencia habitual, para realizar tareas solidarias y manifestar su creatividad, especialmente en campos artísticos y culturales, en el comercio, la cocina y la gastronomía, los turistas disfrutan participando de los modos de vida de los lugares que visitan, de sus manifestaciones festivas y de todo lo que contribuye a mostrar originalidad, sean Noches en Blanco, Noche de los Museos o Visita a vestigios industriales del pasado o a empresas vivas (Zárate Martín, 2011). La visita a los museos es parte de ese contexto y explica el creciente interés por conocerlos, incluso los que no figuran en las listas de los grandes pero que sí facilitan la interpretación de los lugares.

\section{DE LA CONSERVACIÓN DE FONDOS A OFERTA CULTURAL}

Las opiniones vertidas en el portal TripAdvisor sobre los atractivos de los lugares y sobre todo de las ciudades revelan enseguida el protagonismo de los museos como atracción turística. En Bilbao, el Guggenheim es citado como la principal de las 100 "cosas" recomendables para cualquier visitante, con 8.994 opiniones. En Madrid, el Museo del Prado es señalado con 32.570 opiniones como lo primero que se debe visitar, seguido del Thyssen-Bornemisza con 9.684 opiniones y del Reina Sofía con 9.294. Los tres museos, calificados de excelentes, justifican que Madrid figure entre las ciudades del mundo con mejores museos, y todavía habría que añadir a ellos el museo del equipo de fútbol del Real Madrid, que ocupó en 2016 la tercera posición por número de visitantes, con más de un millón, y la primera por ingresos.
Madrid ha pasado de tener veintiún museos en 1948 a noventa y nueve en nuestros días, muchos proceden del siglo XIX y del primer tercio del XX, pero es a partir de 1960 y 1970 cuando empezaron a aumentar más y a generalizarse como atracción turística, coincidiendo con la irrupción del turismo de masas. Sus piezas y colecciones, como sus edificios e instalaciones, empezaron a ser utilizados por entonces como propaganda de la ciudad a través de carteles y folletos, y a aportar ingresos significativos por el número de visitantes (Fernández Fuster, 1991). Antes las visitas eran escasas y la gestión museística se centraba en el acopio y catalogación de materiales para su conservación, con poca preocupación por exponerlos de manera atractiva.

No obstante, el origen de los cambios en la forma de gestionar y presentar las colecciones de los museos españoles se remonta a los 1930, bajo la influencia de exposiciones internacionales organizadas desde principios de siglo en algunos países y de ciertas muestras emblemáticas. El primer Congreso Internacional de Museos en Madrid, en 1933, actuó como revulsivo (Nieto Gallo, 1973a), pronto interrumpido por la Guerra Civil. Terminada la contienda, como señala Fernández Fuster (1991), se abrió una etapa compleja que obligó a concentrar los esfuerzos en la reparación de los edificios y en la recuperación de colecciones que habían sido trasladadas para evitar hurtos y desperfectos. La reapertura se produjo pronto, pero en medio de carencias de todo tipo. En Madrid, el Museo del Prado volvió a abrir el 7 de julio de 1939; a continuación, el Museo Arqueológico Nacional (1940), el Museo del Ejército (1941), el Museo Pedagógico (1942) y el Anatómico del Doctor Villa (1942), al tiempo que se abrieron algunos nuevos (Nieto Gallo, 1973a). De ese modo, en 1948 había ya veintiún museos en funcionamiento.

Los Anuarios Estadísticos de España muestran ya el protagonismo del Museo del Prado en los 1950, el más frecuentado con diferencia con casi la mitad de las visitas a museos. Le siguen otros museos del eje del Paseo del Prado y de Recoletos, revelando la temprana importancia cultural de este espacio dentro de la ciudad. El Museo del Prado pasó de 265.321 visitantes en 1948 a 391.915 en 1957, un volumen apreciable respecto a datos anteriores: 122.210 visitantes en 1916 y 124.000 en 1919. Ese aumento da cuenta de su creciente proyección y justifica las actuaciones que se acometieron entonces para mejorarlo, con donaciones y adquisiciones que elevaron sus fondos en 1969, en el 150 aniversario de su fundación, a "3.147 cuadros, 498 esculturas, 3.200 dibujos, 9 tapices y 126 piezas de orfebrería" (Museo del Prado. Enciclopedia. 
Cronología del Museo), y la primera reforma (19431946) según proyecto de Pedro Muguruza, dirigida a reparar los daños de la guerra, sustituir materiales combustibles, renovar la luz eléctrica y habilitar nuevas salas. En el exterior, en la fachada norte, se construyó la escalera que da acceso actualmente a la segunda planta y enfrente se colocó la estatua de Goya. Un segundo proyecto de ampliación, de Fernando Chueca Goitia y Manuel Llorente Junquera, ejecutado entre 1954-1956, añadió otras dieciséis salas (Museo del Pardo. Enciclopedia. Cronología del Museo).

En el conjunto de España, el aumento de museos entre 1948 y 1971 estuvo también impulsado por la demanda de turistas y residentes. De 147 museos en 1948 se pasó a 626 en 1971 (Nieto Gallo, 1973b), aunque la distribución espacial no fue homogénea. Las provincias de Barcelona y Madrid concentraron el mayor número, aunque su peso relativo descendió por el aumento de museos en otras provincias. Algunos de los mayores avances se produjeron en las Islas Baleares (de cuatro museos en 1948 a veintinueve en 1970), en Gerona (de seis a veinticinco museos), en Valencia (de nueve a veintidós), y en localizaciones interiores, como Sevilla y Toledo, que figuran en 1971 entre las diez provincias con más museos del país, como consecuencia de la abundancia de restos y bienes culturales susceptibles de ser recogidos en los museos, de la distribución de la población y de la desigual incidencia del turismo en el territorio, muy volcado hacia el litoral mediterráneo y las islas por sus atractivos de sol y playa, y hacia las principales ciudades del país.

De manera simultánea, los museos emprendieron un proceso de renovación en su gestión y en la exposición de sus fondos para adecuarlos a los nuevos tiempos siguiendo las pautas de los museos de Estados Unidos y de Europa desde los 1940 (Bolaños, 1997), con nuevas tecnologías para la exhibición museográfica y criterios organizativos originales, dentro de una concepción del museo "cada vez más funcional y democrática", más abierta a la sociedad y a la necesidad de dar respuesta al incremento de visitantes (Bolaños, 1997). En Madrid fueron ampliados y reorganizados el Museo Arqueológico Nacional, el Museo de Arte Moderno, el de Carruajes y el de la Real Armería, al tiempo que se abrían otros, como los del Grabado Contemporáneo, de la Administración, de la Ciencia y la Técnica, de la Aeronáutica, la Fábrica Nacional de la Moneda y Timbre, del Ferrocarril y los Monasterios de las Descalzas Reales y de la Encarnación. A su vez, el crecimiento continuo de visitantes en el Museo del Prado, que alcanzó 1.020.691 en 1975 (Cañas, 1986,
1 de agosto), propició nuevos programas de modernización, de mejora de sus salas y de protección de cuadros, e incluso de ampliación de plantilla. A partir de aquellos años, el Museo del Prado se afirmó como principal atractivo turístico de Madrid, no solo por sus colecciones sino por su edificio y los valores medioambientales y paisajísticos de su entorno.

La reanudación de los ayuntamientos democráticos tras la aprobación de la Constitución de 1978 supuso otro impulso para la vida cultural y los museos, al tiempo que la revolución de las Tecnologías de la Información y la Comunicación (TIC) y los cambios de modelo productivo y social, con aumento de tiempo libre y más facilidades para la movilidad, potenciaron el ocio y turismo, y consecuentemente la visita de museos, hasta convertirla en fenómeno de masas y elemento dinamizador del turismo. Los responsables de la gestión de los museos multiplicaron sus esfuerzos para abrirlos al público y aumentar los visitantes, convencidos de su papel no solo como conservadores de recursos patrimoniales sino como trasmisores de valores culturales que ayudan a comprender el presente a través del pasado y de la comunicación mediante exposiciones, conferencias y otras actividades. Por otra parte, la mejora económica y el aumento del nivel de formación de la población, junto con el afán de descubrimiento, aceleran las visitas a los museos y sus procesos de creación, reforma, renovación y mercantilización con la venta de recuerdos de todo tipo.

El incremento de la atracción de los museos es favorecido, además, como señalan J. Ballart Hernández y J. Juan i Tresserras (2008), por "la progresiva mundialización de las relaciones políticas, económicas y culturales", la ampliación por la Administración de "responsabilidades sociales en asuntos relacionados con la cultura" y la "aceleración de los procesos de regionalización y descentralización administrativa" que favorecen el redescubrimiento del territorio cuando son mayores las amenazas de pérdida de identidad por la globalización de la economía y de la cultura. De ese modo, el desarrollo museológico y patrimonial desde la segunda mitad del siglo XX, con la consiguiente renovación de los museos, de sus instalaciones y de su gestión, se inserta dentro de estrategias que revalorizan lo local y se benefician del aumento de interés por los bienes culturales como consecuencia de la extensión de la educación y de una sociedad más participativa e informada por los medios de comunicación, todo en un marco de vida que impulsa la "mercantilización de la cultura" a través del turismo y las actividades recreativas. 


\section{COMPETENCIA POR LOS VISITANTES DESDE CRITERIOS DE SOSTENIBILIDAD TURÍSTICA}

Dentro de esa concepción "mercantil de la cultura", como "subproducto de una sociedad de masas, abierta, democrática y económicamente avanzada" (Ballart Hernández y Juan i Tresserras, 2008), la empresa museística trata de adecuarse a nuevas maneras de exponer sus fondos para lograr mayor competitividad. Así, en los 1990, los museos avanzan desde una concepción receptiva en la que las reformas se dirigían a mejorar la legibilidad de los contenidos y prestar mayor atención en el servicio (mejores dotaciones, tienda, cafetería, folletos y publicaciones en varios idiomas...), siempre dentro del museo, a una gestión que incorpora el marketing y la atracción de visitantes desde criterios de sostenibilidad como objetivos principales. De ese modo, los museos salen fuera de sus edificios, se promocionan como un producto más de consumo, se dan a conocer y definen estrategias de captación que se materializan en exposiciones itinerantes, en el intercambio de fondos e incluso en la creación de extensiones en ciudades distintas de las de su sede: el Guggenheim de Nueva York en Bilbao, el Hermitage de San Petersburgo, el Centro Cultural Pompidou y el Thyssen-Bornemisza en Málaga, o el Louvre en Abu Dhabi. Se entra así en una dinámica en la que los museos se afirman como referencia para demandas de consumo cultural de las poblaciones locales y de los que acuden de fuera para conocer, disfrutar y experimentar las emociones que trasmiten las obras expuestas, al tiempo que esa dinámica ayuda a conservar edificios y a mejorar entornos paisajísticos y, por lo tanto, a la sostenibilidad del territorio. En todos los casos, los grandes museos se convierten en "visita obligada" para los turistas, seducidos por la propaganda, las guías de turismo, las "visitas virtuales" a través de Internet, los paquetes de los turoperadores y las ofertas hoteleras. La presentación de obras de arte únicas y las exposiciones temporales publicitadas con técnicas de marketing refuerzan su atracción. Y ese objetivo se consigue también mediante la promoción de prácticas que facilitan la interacción, como sucede en la Ciudad de las Artes y las Ciencias de Valencia con carteles de "Prohibido no tocar".

La influencia de este proceso se materializa en el aumento de los museos y de su variedad temática. Así, según los últimos datos disponibles en 2017 del Ministerio de Educación, Cultura y Deporte, de poco más de 500 museos en España en los 1960 se pasó a 1.522 en 2014 y los visitantes crecieron de 38.067 .315 en 2000 a 116.836 .684 en 2014 , aunque la proporción de ciudadanos que los frecuentan respecto al conjunto de la población siguió siendo baja, alrededor del 30\% de la población. La Comunidad de Madrid, con 130 museos, ocupa la quinta posición por museos dentro de España, seguida de Cataluña y precedida por Castilla-León, Castilla-La Mancha, Comunidad Valenciana y Andalucía, si bien si el cómputo se hace por provincias, la de Madrid sigue siendo la que concentra el mayor número de museos y es la primera por el volumen de visitantes.

En la ciudad de Madrid, el aumento del número de museos ha sido constante desde 1975, de 59 a 99 en la actualidad. Los nuevos museos corresponden a distintas tipologías y se ubican en zonas muy variadas, la mayoría de las veces facilitando la recuperación de edificios concebidos para otros usos y en avanzado estado de deterioro material. Entre los museos y salas de reciente creación en zonas de anterior implantación museística destacan el Museo Nacional Centro de Arte Reina Sofía, creado en 1988 en el antiguo Hospital de San Carlos, el Thyssen-Bornemisza, que comenzó a funcionar en 1992 en el Palacio de Villahermosa, rehabilitado entre 1988 y 1992, el Caixa-Forum, aprovechando una antigua central de electricidad, inaugurado en 2008, y la Fundación Mapfre, abierta también en 2008 en el antiguo Palacio de la duquesa de Medina de las Torres, construido entre 1881 y 1884 . Todo ello contribuye a reforzar el eje centro económico y social de la ciudad.

El Museo del Prado, el Museo Naval, el de la Biblioteca Nacional, el Museo Arqueológico Nacional, el Museo de Cera, el Museo Tiflológico de la ONCE y el Museo del Real Madrid hacen del eje del Prado-Paseo de Recoletos-Castellana uno de los espacios de mayor densidad museística del mundo, reseñado en todas las guías y páginas web del turismo, con un elevado número de visitantes, la mayoría de fuera de Madrid. Sus museos son los más visitados, sobre todo el Museo Nacional del Prado, el Museo Nacional Reina Sofía y el Museo Thyssen-Bornemisza, los tres recibieron el $68.5 \%$ de los visitantes totales de los museos de la ciudad en 2015. Por otra parte, en el mapa de distribución espacial de los museos de Madrid a partir de la aplicación de un índice de especialización funcional, tras el eje comentado, con una prolongación hacia el sur por la Ronda de Valencia y hacia el norte por el Paseo de la Castellana, se dibuja otro eje museístico este-oeste, desde Cibeles por la calle de Alcalá hasta el Palacio de Oriente y sus inmediaciones, siempre en el distrito Centro, que concentra la mayor oferta cultural y turística de la ciudad. También destaca la especialización museística del noroeste de la ciudad por instalaciones de esta naturaleza asociadas a las universidades Complutense y Autónoma. 
Figura 1. Número de visitantes a museos del eje Prado-Recoletos y del resto de la ciudad de Madrid

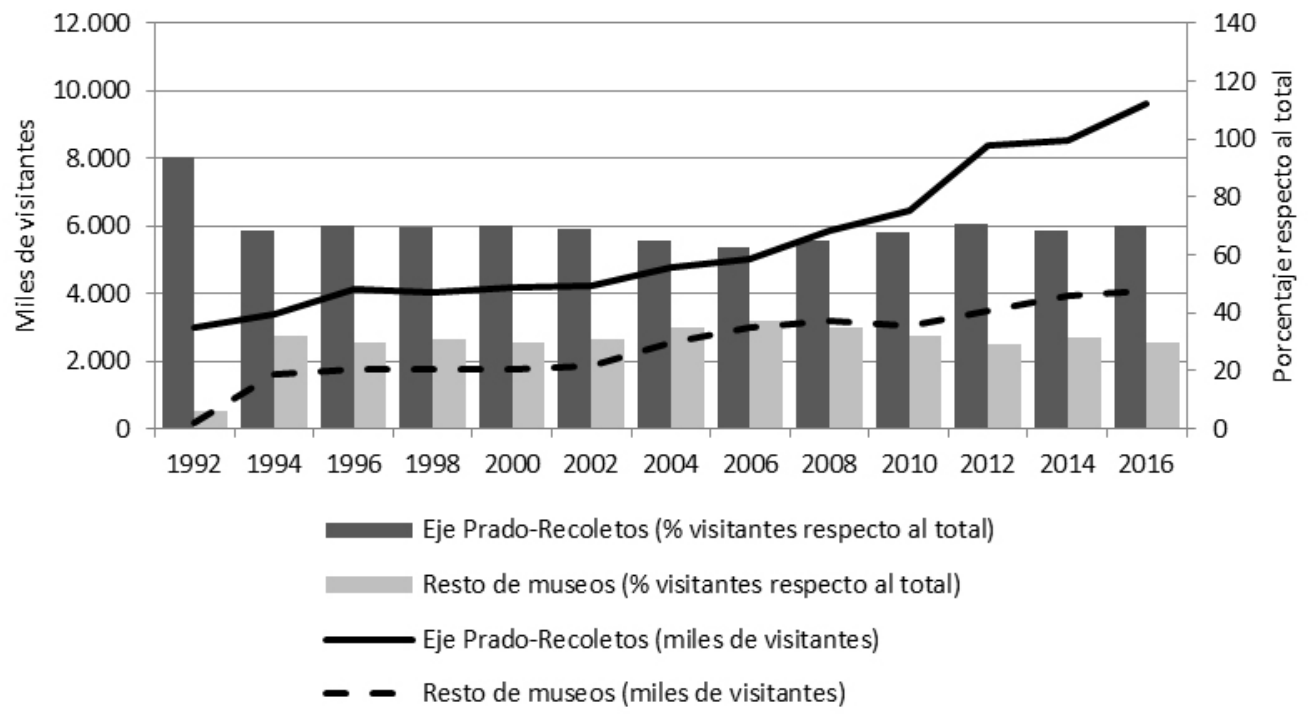

Fuente: Banco de Datos Estadísticos del Ayuntamiento de Madrid. Extraído de García Ferrero (2016) y actualizado para el año 2016 con datos de la misma fuente.

Figura 2. Especialización funcional por distritos, barrios y secciones de Madrid en museos (Índice de Davies) en 2015

Fuente: García Ferrero (2016).

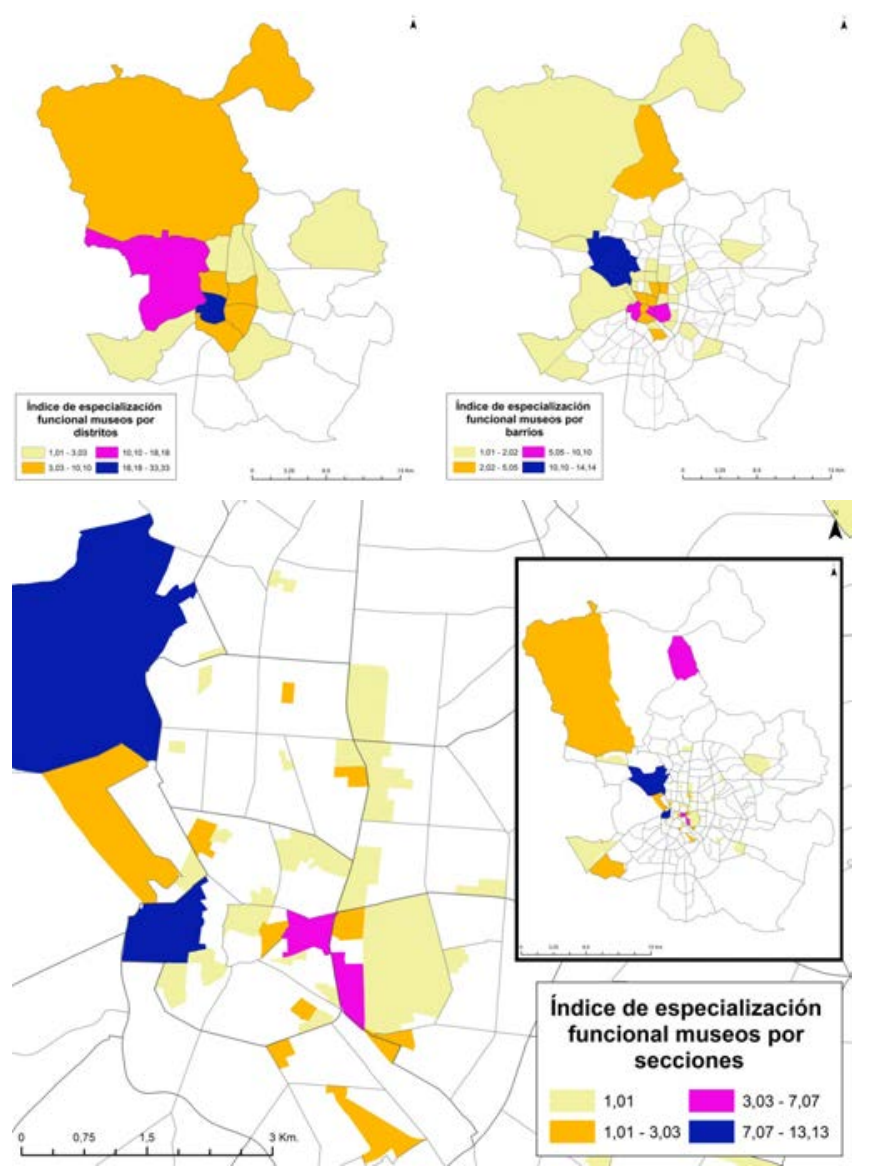


Figura 3. Valoración global de los museos de Madrid y veinte primeros museos con valoración excelente en la web turística TripAdvisor (mayo de 2016)

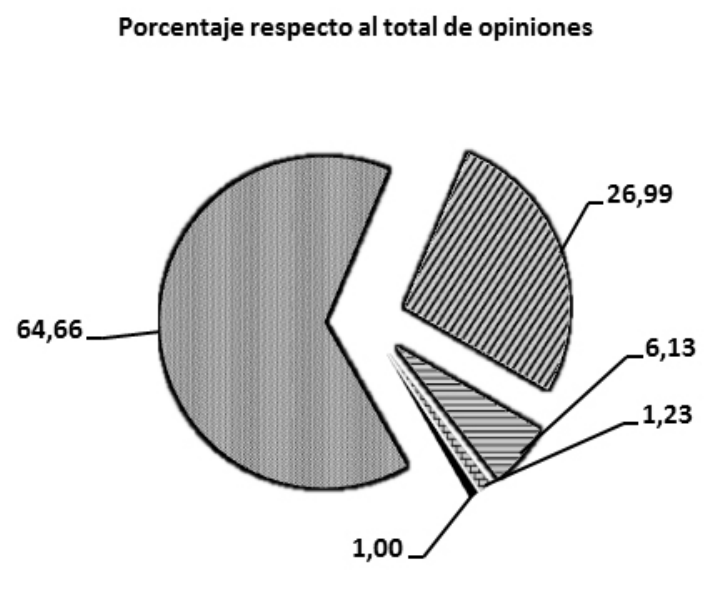

圈Excelente Muybueno ENormal a Malo Pésimo

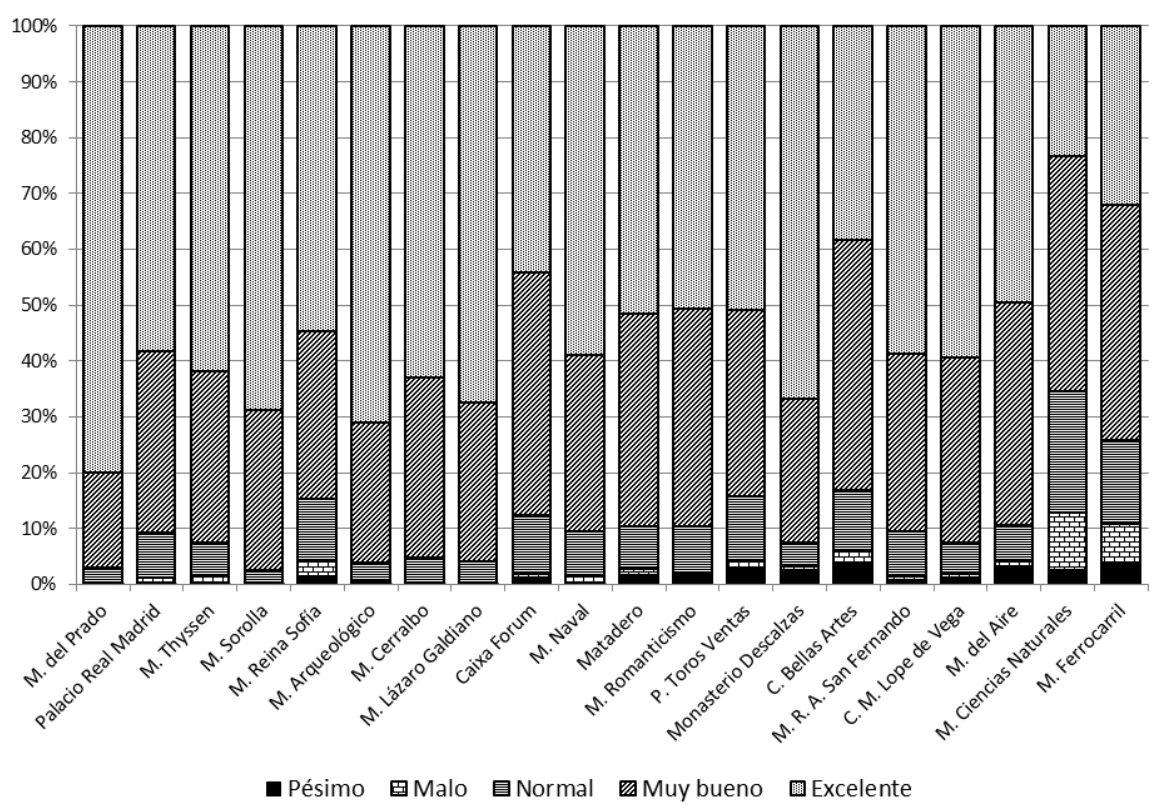

Fuente: García Ferrero (2016).

\section{VISITANTES DE MUSEOS, UN PÚBLICO CON NIVEL DE FORMACIÓN MEDIO ALTO}

Los datos de visitantes del Ministerio de Cultura demuestran la importancia de los turistas extranjeros en la entrada a los museos y de manera especial a los más emblemáticos, el Reina Sofía y el Prado, ambos entre los veinte museos más visitados de Europa en 2015, el primero con más de 3,2 millones de visitantes, en la posición 11.a , y el segundo con casi 2,7 millones, en la 13. a posición. La entrada de turistas extranjeros se halla muy concentrada. Así, la media de extranjeros por museo en el conjunto de España es del $18,1 \%$, pero ese porcentaje se eleva hasta el $50,5 \%$ en la Comunidad de Madrid y valores inferiores en el País Vasco $(42,8 \%)$, Canarias $(20,4 \%)$, Baleares $(19,6 \%)$ y Andalucía (18,3\%). En el primero de los casos se explica porque la Comunidad de Madrid es un destino cultural que ha pasado de ocho millones de visitantes en 2014 a trece en 2016, entre nacionales y extranjeros; en el País Vasco, por su proximidad a la frontera francesa y el efecto del Museo Guggenheim en Bilbao, y en Canarias, Baleares y Andalucía por el 
atractivo consolidado de sus litorales con magníficas condiciones medioambientales, instalaciones hoteleras, complejos para prácticas deportivas, parques temáticos y valores culturales, a lo que se une el efecto llamada de la comunicación "boca a boca" de sus residentes extranjeros.

En el Museo del Prado, más de la mitad de sus 2.484.071 visitantes en 2015 fueron extranjeros, un total de 1.451 .575 personas, el $58,4 \%$, y otros 581.981 , el 23,43\%, procedieron de otras Comunidades Autónomas. Por lo tanto, ocho de cada diez visitantes llegan de fuera de la Comunidad de Madrid, según la Encuesta Anual del Instituto de Estudios Turísticos. El 52\% de los extranjeros proceden de cinco países: Estados Unidos, Italia, Francia, Japón y México, y el $72 \%$ de los nacionales de otras Comunidades, lo hacen desde Andalucía, Cataluña, Comunidad Valenciana, Castilla y León y Castilla-La Mancha, en porcentajes relacionados con su volumen demográfico y los flujos turísticos que generan.

Los extranjeros son también numerosos en el Centro Cultural Reina Sofía, el 49,6\%, y en otros museos esa proporción desciende, pero siempre es importante: el 34,4\% en el Museo del Greco de Toledo y el $12,2 \%$ en el Museo Nacional de Arqueología Subacuática (ARQUA) de Cartagena, cuya nueva sede, de arquitectura vanguardista, obra del arquitecto Guillermo Vázquez Consuegra, se inauguró el 26 de noviembre de 2008. El éxito de este museo se explica porque
Cartagena se ha convertido en una ciudad turística a partir del descubrimiento de su teatro romano y de una estrategia sistemática de recuperación de los vestigios arqueológicos de su pasado, especialmente cartaginés, romano, visigodo y bizantino (Morales, 2016). Además, Cartagena, como Málaga, se beneficia de haberse convertido en punto de atraque de cruceros: en 2017 está previsto que hagan escala 148 barcos con más de 230.00 viajeros.

En cuanto a las variables sociales y demográficas de los visitantes, es significativa la asociación entre el interés por la visita y el nivel de formación. En el Museo del Prado, la mayoría son personas con estudios superiores, el $65 \%$, y los menos, las personas con estudios primarios, el 5,2\%, y por edades, el 76\% tiene entre 18 y 55 años, son las cohortes de población más numerosas y de mayor movilidad por razones económicas, de ciclo vital y de interés por el turismo cultural. Como una prueba más del perfil cultural de los visitantes del Museo del Prado, el 97\% declara frecuentar de manera habitual museos y exposiciones, el $36,65 \%$ considera obligada la entrada a este museo si se viene a Madrid, y el 32,79\% afirma que la visita responde a un interés personal. De ese modo, se hace patente el predominio entre sus visitantes de colectivos atraídos por los valores patrimoniales a los que se sumarían los vinculados al turismo de negocios que aprovechan parte de su tiempo libre para ver museos. Todo ello nos proporciona el perfil de un visitante de poder

Figura 4. Motivos de la visita al Museo del Prado en 2015 en \%

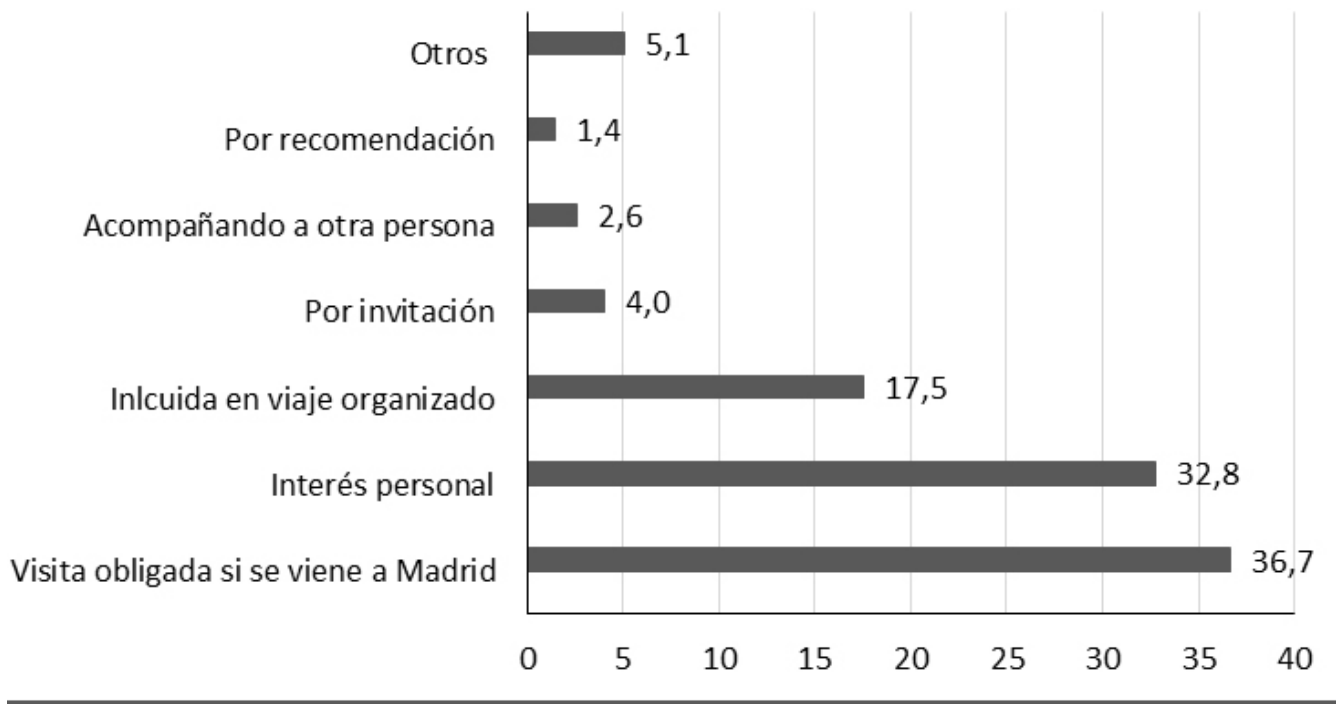

Fuente: Elaboración propia a partir de los datos de la Encuesta de hábitos y prácticas culturales del Ministerio de Educación, Cultura y Deporte. 
adquisitivo por encima de la media, con un nivel de gasto de $1.152,4 €$ por persona y de $158,7 €$ al día en el caso de los turistas de negocio, según la Encuesta de Gasto Turístico del Instituto de Estudios Turísticos (IET). Eso se traduce en un turismo selecto que demanda alojamiento y restauración de calidad, lo que se deja sentir en el paisaje de los principales espacios culturales madrileños: el eje del Paseo del Prado-Recoletos-Castellana y las inmediaciones del Palacio de Oriente y la Gran Vía.

Los informes sociales del Laboratorio Permanente de Público de Museos del Ministerio de Cultura confirman los datos anteriores. En todos los casos, predominan los visitantes con estudios superiores; por ejemplo, en el Museo Nacional Centro de Arte Reina Sofía, el 70,7\% detentaba ese nivel de formación en 2013; en el Museo del Greco en Toledo, el 61,6\% en 2015, y en el Museo Nacional de Arqueología Subacuática (ARQUA) de Cartagena, el 49,2\%. A su vez, la Encuesta de hábitos y prácticas culturales en España en 2014-2015, del Ministerio de Cultura, ratifica el elevado porcentaje medio de visitantes con estudios superiores de los museos, el $47 \%$.

El papel de los museos como generador de flujos turísticos y potenciador de la actividad turística se pone también de manifiesto a través de la Encuesta sobre percepción y valoración del paisaje cultural en ciudades históricas, parte de nuestro proyecto de in- vestigación Dinámicas comparadas para una gestión sostenible de los paisajes culturales a través del turismo. La encuesta fue realizada por teléfono dentro del ámbito nacional en 2014, según un cuestionario preestablecido. El universo se delimitó a mayores de dieciocho años en municipios de más de 20.000 habitantes que habían visitado en los anteriores tres años alguna ciudad monumental. Los resultados dieron cuenta del carácter selectivo de la visita a museos, pero también de su menor interés para los encuestados si se hacía abstracción de su nivel de formación. De este modo, "entrar en museos" ocupa una séptima posición como motivación para visitar una ciudad histórica, por detrás de "recorrer sus calles", "visitar sus monumentos" y "contemplar panorámicas o vistas generales", lo que no sorprende sabiendo que un tercio de la población no visita nunca o casi nunca museos, según la Encuesta de hábitos y prácticas culturales en España del Ministerio de Cultura de 2014-2015. En cambio, cuando se considera la formación de los encuestados, "visitar museos" ocupa una sexta posición entre los motivos de atracción, lo que confirma más la vinculación entre nivel de estudios y entrada a museos y exposiciones. Todo nos lleva, pues, a concluir la relación entre la visita a museos y el nivel de formación, el público que acude a los museos no responde al perfil de la mayoría de los turistas y está por encima del nivel cultural medio de la sociedad.

Figura 5. Visitantes de museos por nivel de estudios en 2015 en \%

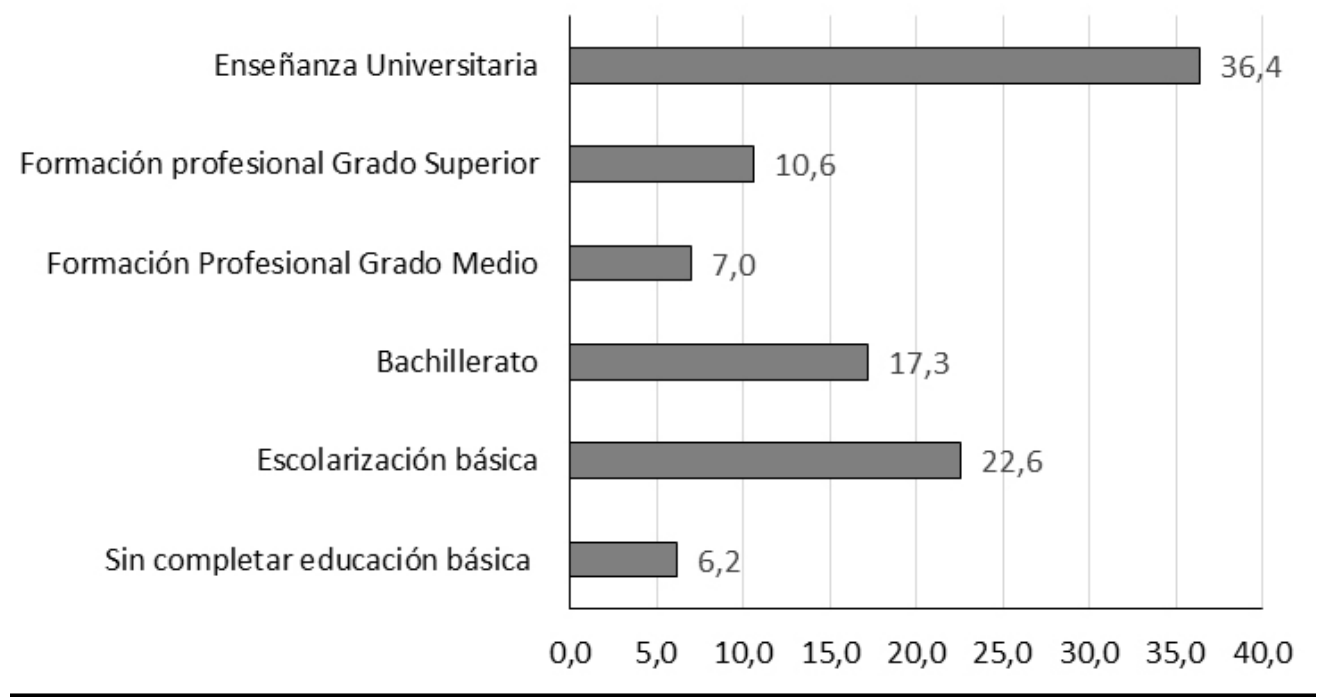

Fuente: Elaboración propia a partir de los datos de la Encuesta de hábitos y prácticas culturales del Ministerio de Educación, Cultura y Deporte. 


\section{SOPORTE PARA LA CONSERVACIÓN DEL PATRI- MONIO Y LA MEJORA DEL PAISAJE}

La creciente atracción de los museos y de las exposiciones temáticas refuerza el turismo cultural y su concentración en ambientes urbanos, pero si sus efectos económicos y sociales son indudables no lo son menos en cuanto a su contribución a la conservación del patrimonio edificado y puesta en valor del paisaje. De este modo, el turismo de museos participa de criterios de sostenibilidad y de responsabilidad social recogidos en la Convención del Patrimonio Cultural y Natural de la UNESCO de 1992, en el Convenio Europeo del Paisaje de 2000 y en leyes autonómicas del patrimonio histórico y cultural, como la de Madrid (Ley 2/ 2013, de 18 de junio), que empiezan a incluir el concepto de paisaje cultural y la necesidad de su preservación y puesta en valor (Zárate Martín, 2016).

La participación en la conservación y mejora del patrimonio construido comenzó con la instalación de los primeros museos en edificios de valor históricoartístico y va a más desde la década de 1970, cuando muchos de los nuevos museos aprovechan antiguas estructuras de diferente uso (Chinchilla Gómez, 2005), salvándolas de la demolición, como el Museo d’Orsay en París, inaugurado en 1986 en la estación de la Compañía de ferrocarriles de Orleans, abierta en 1900 con ocasión de la Exposición Universal de aquel año. En todas partes, este proceso ha ido unido al urbanismo de la recuperación y a la renovación de las empresas museísticas en cuanto a su concepto y a su presentación pública. Gracias a este proceso se han creado nuevos museos, se han remodelado edificios históricos y se han mejorado paisajística y socialmente muchos de sus entornos, con lo que se acrecienta el papel de los museos respecto a la conservación del patrimonio, no solo de los contenidos que guardan sino también de sus continentes y espacios en los que se ubican. Por otra parte, las reformas de los museos se ajustan desde entonces a objetivos de sostenibilidad medioambiental y energética. También la regulación de los flujos de visitantes es motivo de atención para garantizar la seguridad de los fondos.

La inauguración de la Ciudad de las Artes y de las Ciencias el 1 de abril de 1998, en el cauce antiguo del río Turia en Valencia, diseñada por Santiago Calatrava y Félix Candela, impulsó una de las mayores operaciones de renovación y de mejora de paisaje en una ciudad, además de convertirse en el principal motivo de atracción turística de Valencia, lo mismo que ha sucedido en Bilbao con el Museo de Arte Contemporáneo Guggenheim, diseñado por Frank O. Gehry e inaugurado el 17 de octubre de 1997, en el marco de la operación urbanística Ría 2000, y con una cifra de 1.103.211 visitantes en 2015 de los que el $65 \%$ son extranjeros. Los efectos de ambas actuaciones sobre el turismo son manifiestos. Así, de 401.454 viajeros registrados en los hoteles de Bilbao en el año 2000 se pasa a 884.673 en 2016, lo que representa un crecimiento de 220 en la segunda fecha respecto al índice 100 en la primera, y de 813.020 viajeros en Valencia en el año 2000 a 1.752 .626 en 2016, con un índice de crecimiento del 216 sobre 100 en ese mismo periodo.

Figura 6. Museo Guggenheim, Bilbao

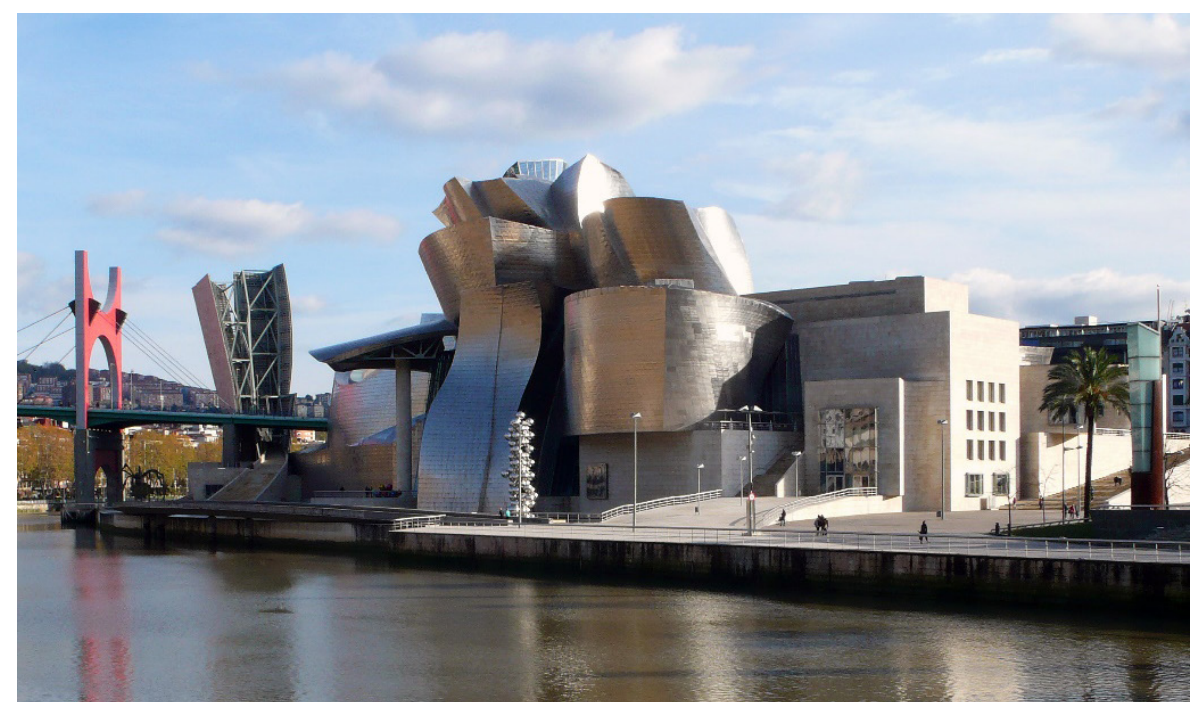

Fuente: Fotografía A. Zárate Martín. 
Tabla 1. Evolución de viajeros respecto al índice 100 en 2000

\begin{tabular}{|l|c|c|c|c|}
\hline & \multicolumn{4}{|c|}{ Años } \\
\hline Ciudad & $\mathbf{2 0 0 0}$ & $\mathbf{2 0 0 5}$ & $\mathbf{2 0 1 0}$ & 2016 \\
\hline Granada & 100 & 106 & 107 & 143 \\
\hline Madrid & 100 & 120 & 160 & 183 \\
\hline Málaga & 100 & 121 & 228 & 310 \\
\hline Toledo & 100 & 111 & 118 & 150 \\
\hline Valencia & 100 & 159 & 190 & 216 \\
\hline Valladolid & 100 & 116 & 132 & 161 \\
\hline Bilbao & 100 & 132 & 168 & 220 \\
\hline Cartagena & 100 & 250 & 231 & 256 \\
\hline
\end{tabular}

Fuente: Elaboración propia a partir de los datos de la Encuesta de ocupación hotelera del INE.

Otro caso significativo es el de Málaga, con un incremento de visitantes aún mayor, de 377.873 en 2000 a 1.170.555 en 2016, un aumento de 310 respecto al índice 100 en el primer año. A los atractivos de sol y playa de la Costa del Sol, de sus campos de golf y parques temáticos, se añaden los de sus recursos patrimoniales y, sobre todo, en el caso de su capital, su transformación en ciudad de museos, estrechamente unida a la rehabilitación de su centro histórico y a la renovación de su frente marítimo. Todo ha sido favorecido por una política portuaria que hace de Málaga escala para cruceros que recorren el Mediterráneo, 238 en 2015, según su Autoridad Portuaria y se esperan 296 para 2017 con una previsión de 500.000 turistas.

Málaga cuenta, además, con un Plan Estratégico de Turismo 2016-2020 que apuesta por la sostenibilidad como criterio prioritario y que crea la sub-marca Ciudad de Museos para potenciar su imagen como destino turístico, al tiempo que se propone la candidatura de su paisaje urbano como Patrimonio de la Humanidad. Para alcanzar esos objetivos, resulta fundamental el papel de los museos creados en la ciudad y sobre todo el impulso que dan al turismo los más emblemáticos, como el Museo Picasso, abierto en octubre de 2003 en el palacio de Buenavista, antigua sede del Museo de Bellas Artes; el Centro de Arte Contemporáneo (CAC), abierto también en 2003 en el Antiguo Mercado de Mayoristas de 1927; la sección delegada del Museo Thyssen en el Palacio de Villalón del siglo XVI desde marzo de 2011 y la representación del Museo Hermitage de San Petersburgo en el edificio rehabilitado de la Tabacalera de 1920. A todo ello se añade lo que supone para la imagen de la ciudad la instalación en ella de la primera delegación del Centro Pompidou fuera de Francia. Este museo se ubica en un edificio vanguardista, el Cubo, erigido en 2013 en el puerto. Sólo el CAC, el Museo Picasso y el Thyssen, entre los tres, recibieron un total de 745.596 visitantes en 2016.

Los anteriores ejemplos y otros muchos en la geografía española, entre ellos el Museo Nacional de Arqueología Subacuática (ARQUA) de Cartagena o el Museo Nacional de Arte Romano de Mérida, servirían también de muestra de cómo los principales estudios de arquitectura trabajan en el diseño de los museos para convertirlos en hitos del paisaje urbano, de la misma manera que intervienen en la remodelación de edificios históricos para usos museísticos. En nuestro país esta segunda tendencia es favorecida por la variedad y riqueza del patrimonio histórico de carácter inmueble, lo que ha permitido aprovechar multitud de edificios históricos para museos. Así, a través de una arquitectura cargada de valores histórico-artísticos propios y valores tradicionales se incorporan atractivos adicionales a los museos y se contribuye a "mantener vivo el patrimonio" (Fernández Sabau, 2009-2010, p. 42), con lo que se hace más que evidente la contribución del turismo a la sostenibilidad del territorio y del paisaje, de acuerdo con los criterios de la Carta del Turismo Sostenible de la Organización Mundial del Turismo (OMT), 1995: "El desarrollo turístico debe de ser soportable a largo plazo en el plano ecológico, viable económicamente y justo en el plano ético y social para las poblaciones locales". En la Cumbre sobre Turismo Sostenible +20 , celebrada el 26 y 27 de noviembre de 
2015 en Vitoria-Gasteiz, se ratificó la validez de los anteriores principios y se expresó como objetivo "preservar nuestro patrimonio común", lo que bien cumplen los museos en sí mismos y a través de sus efectos sobre el entorno social y económico, y sobre el paisaje.

En Madrid, la renovación de los museos favoreció la revitalización funcional y la mejora de la calidad ambiental y social de los espacios en los que se ubican (Montaner Martorell, 2005), además de permitir salvar estructuras arquitectónicas que de otro modo habrían desaparecido, como ocurrió especialmente entre 1950 y 1975, entre ellos el Mercado de la Cebada, inaugurado por Alfonso XII en 1875 según el modelo parisino de les Halles y demolido en 1956. Muchos de los museos y centros culturales nuevos ocupan ahora antiguos edificios civiles, eclesiásticas y militares, la mayoría con algún nivel de protección como Bien de Interés Cultural (BIC) y bastantes estuvieron amenazados de desaparición. Esto es lo que sucede también con fábricas e infraestructuras procedentes de las dinámicas de vaciado industrial desde los 1970 (Pardo Abad, 2004) y de las transformaciones de su sistema ferroviario.

Entre los ejemplos madrileños más significativos de estas antiguas instalaciones figuran las fábricas de cervezas Mahou (1892) y El Águila (1912-1914), la primera, que acoge el Museo de ABC del Dibujo y la Ilustración, inaugurado en 2010, y la segunda, declarada BIC en 1990 y rehabilitada a principios de 2000, que alberga la Biblioteca y Archivo Regional de la Comunidad (García Pérez et al., 2003b, pp. 152-153). Especial importancia tiene la Estación de Delicias, de 1880, que tras su cierre al tráfico de viajeros (1969) y de mercancías (1970) fue restaurada para Museo del Ferrocarril y exposiciones del Museo Nacional de la Ciencia y la Tecnología. No menos relevantes son el antiguo Matadero y Mercado Municipal de Ganados, las infraestructuras del Canal de Isabel II y la Fábrica de Tabacos de la Glorieta de Embajadores, del siglo XIX. En ese mismo contexto, Metro de Madrid ha habilitado también dos museos, Conjunto Andén Cero, para dar a conocer su patrimonio: la antigua Estación de Chamberí y la Nave de Motores de Pacífico para suministro eléctrico, en funcionamiento desde 1923 hasta 1972. Ambas instalaciones actúan como Centros de Interpretación del Metro de Madrid, y a su vez, la Empresa Municipal de Transportes (EMT) ha abierto en 2016 un museo en una nave prototipo de la arquitectura industrial madrileña de finales de los 1950.

La actividad museística ha permitido igualmente la conservación de tipologías residenciales. La mayoría ofrecen elementos de singularidad y algunas han sido residencia de personajes ilustres. Así, la Casa de Lope de Vega es una muestra de la arquitectura residencial del siglo XVII. Esta casa, declarada BIC en 1935, cuando "se cumplían trescientos años de la muerte del escritor" (García Pérez et al., 2003a, p. 44), integra enseres, ajuar y bienes de otras colecciones. Del mismo modo, la casa donde vivió y murió hacia 1172 San Isidro labrador, reconstruida desde finales de 1980 y a lo largo de la década de 1990, alberga el Museo de San Isidro y los Orígenes de Madrid, con el pozo del milagro, un patio renacentista del siglo XVI y la capilla de los siglos XVII y XVIII. Por su parte, la rehabilitación de una corrala en la calle Carlos Arniches, dedicada a Centro Cultural y, desde 2011, a Museo de Artes y Tradiciones Populares de la Universidad Autónoma de Madrid, ofrece una muestra de una corrala, edificios de viviendas de corredor, una de las manifestaciones constructivas más representativas del madrileñismo (Rodríguez Ariza, 2008, p. 175), de las que quedaban unas cuatrocientas en 1977, y que tan bien describió Pío Baroja (1872-1952) en su novela La Busca, publicada en 1904.

Los museos también han contribuido a conservar la arquitectura palaciega. Entre los antiguos palacios destacan el de Liria, abierto por la casa ducal al público determinados días al año, el de Villahermosa, transformado en Museo Thyssen-Bornemisza, el del Marqués de Linares, convertido en Casa de América desde 1992, y el palacio de la duquesa de Medina de las Torres, transformado en la Sala de Exposiciones Mapfre desde 2008. Otras muestras son el Museo Romántico, fundado en 1924, el Cerralbo, abierto en 1926, el Lázaro Galdiano, inaugurado en 1951, la Casa Museo de Joaquín Sorolla, desde 1931. El 1 de junio de 2017 ha abierto un museo la Fundación Foster en el antiguo palacete del Duque de Plasencia (en la Calle Monte Esquinza esquina a Jenner). Cuenta con archivo, salas temáticas, maquetas de los edificios diseñados por Sir Norman, e incluso un trozo del muro de Berlín y un automóvil que perteneció a Le Corbusier y admitirá grupos de visitantes determinados días a la semana.

También se han aprovechado edificios asistenciales, como el Museo Nacional Centro de Arte Reina Sofía en el antiguo Hospital de San Carlos, el Museo Carlos de Amberes en la Fundación Carlos de Amberes, y el Museo de Historia de Madrid, fundado en 1929, en el antiguo Hospicio de San Fernando, obra del XVIII de Pedro de Ribera. Es igualmente significativa la reutilización de edificios militares, como el Museo de Arte Contemporáneo de Madrid en el cuartel del Conde Duque, también de Pedro de Ribera, y el Castillo de la Alameda de Osuna. Tampoco faltan los edificios de 
servicios dedicados a museos y exposiciones, como el Centro Socio-Cultural La Casa Encendida, inaugurado en 2002 por Caja Madrid en la antigua sucursal de la Caja de Ahorros y Monte de Piedad de Madrid, o el edificio de Telefónica en la Gran Vía, construido entre 1926 y 1929 como el primer rascacielos de España, y cuyo interior acoge exposiciones temporales y una permanente de la historia de las telecomunicaciones.

Por otro lado, la función museística está presente en arquitecturas de muy singular valor monumental como el Palacio Real de Madrid y el Palacio del Pardo, ambas actuando como museos y lugares para la celebración de exposición en sí mismos, pero con usos museísticos anejos, como la Real Armería y la Real Oficina de Farmacia en el Palacio Real o el Museo de la Guardia Real en la Casita del Príncipe del Pardo. A la calidad arquitectónica y singularidad paisajística de Madrid se añaden las fábricas de los grandes museos de la ciudad concebidos específicamente para estos fines: el Museo Nacional del Prado, el Museo Arqueológico Nacional, el Museo Nacional de Antropología, el Museo de Ciencias Naturales y el Museo de América. Todavía habría que incluir en idéntico sentido el Palacio de Velázquez y el Palacio de Cristal en el Parque del Retiro, diseñados para exposiciones a finales del XIX, y edificios de instituciones culturales y científicas, como los de la Real Academia de Bellas Artes de San Fernando y de la Calcografía Nacional, el Museo del Gabinete de Antigüedades en la Real Academia de la Historia y el Museo de la Real Academia de Farmacia. Son igualmente numerosos los museos en construcciones religiosas, como San Antonio de la Florida o San Francisco el Grande y los monasterios de las Descalzas Reales y la Encarnación, a título de ejemplo.

No obstante, uno de los ejemplos más representativos en cuanto a la contribución de la actividad museística al paisaje urbano, comparable a lo que sucede en Berlín en la denominada Isla de los Museos, es el que proporciona la concentración de museos y salas de exposición en los Paseos del Prado y Recoletos y sus prolongaciones por la Castellana hacia el norte y la Ronda de Atocha hacia el sur, con la ampliación del Reina Sofía, proyectada por Jean Nouvel e inaugurada en 2005, la Casa Encendida y la Fábrica de Tabacos. En el entorno de este espacio se encuentran también el Jardín Botánico y el Observatorio Astronómico, dos iniciativas de Carlos III, como también lo fue la reforma del Salón del Prado con las fuentes de Neptuno, Apolo y Cibeles. En la plaza de Cibeles, el Palacio de Telecomunicaciones, de Antonio Palacio, reformado entre 2005 y 2007 para dependencias municipales y
Centro Cultural y de Exposiciones, refuerza la especialización de la zona. Al lado, el Museo Naval, dedicado a la investigación, conservación y difusión de nuestra historia marítima, es una de las instalaciones de mayor crecimiento de visitantes en los últimos años: de 63.752 en 2010 a más de 150.000 en 2016.

Por otra parte, no hay que olvidar que el desarrollo urbanístico del corredor cultural Prado-Recoletos ha ido unido a la historia del Palacio del Buen Retiro y sus jardines. Su construcción en el siglo XVII motivó la proliferación de palacios en sus inmediaciones, entre ellos los ya señalados y convertidos en museos. A finales del siglo XIX y en el primer tercio del XX, este eje urbano se consolidó con el Plan de Ensanche de Carlos María de Castro hacia el norte y el este, y con la construcción del Banco de España, del Ministerio de Marina y de la Bolsa y, muy cerca, del Congreso. Como indica C. Gavira (1981), esta zona era en 1970 el eje del poder político y económico, y de expansión de actividades terciarias, un corredor simbólico y de comunicaciones que el Plan General de Ordenación Urbana de Madrid de 1997 ratifica al retomar como proyecto "la prolongación del paseo de la Castellana por el distrito de Fuencarral", al mismo tiempo que el Plan Especial de remodelación del espacio entre Colón y la Glorieta de Atocha formula su mejora paisajística (Junta de Gobierno del Ayuntamiento, 2 de junio de 2005). Al interés turístico de la zona se suma el atractivo del Parque del Retiro que añade fundamento a la incorporación del Sitio del Retiro y el Prado en calidad de paisaje cultural a la Lista Indicativa Española de Patrimonio Mundial de la UNESCO desde el 18 de noviembre de 2014.

Por último, la calidad ambiental de ese pasillo cultural se ha beneficiado de nuevo con la ampliación del Museo del Prado por R. Moneo, inaugurada el 30 de octubre de 2007, y con los nuevos espacios culturales del distrito meridional de Arganzuela, entre ellos el Museo Ferroviario y el antiguo Matadero Industrial. La aprobación el 11 de noviembre de 2016 de lo que será la segunda ampliación del Museo del Prado en el siglo XXI, integrando el antiguo Salón de Reinos del Palacio del Buen Retiro según proyecto de Norman Foster y Carlos Rubio, añadirá aún más calidad ambiental y paisajística a la zona. A su vez, la Estación de Atocha, edificio rehabilitado que acoge la terminal del AVE, medias distancias y cercanías, permite la celebración de exposiciones en su interior y favorece el dinamismo funcional de todo el espacio señalado en torno a los museos, demostrando una vez más la contribución del turismo a la puesta en valor sostenible de los bienes culturales y del paisaje. 
Figura 7. Recreación de la recuperación del Salón de Reinos para reforma del Museo del Prado

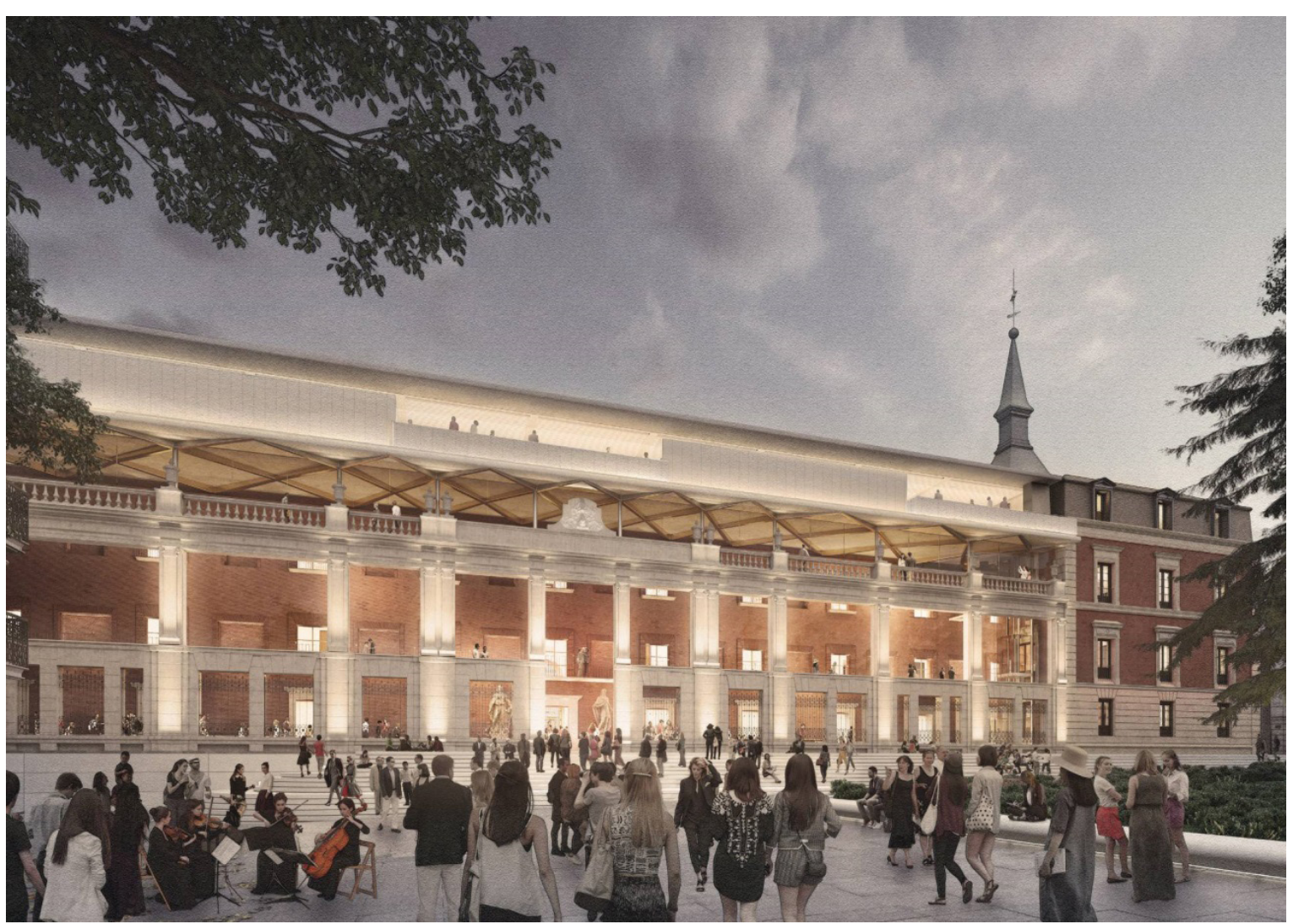

Fuente: Bono (2016, 25 de noviembre).

\section{CONCLUSIÓN: EL TURISMO DE MUSEOS, OPORTUNIDAD PARA LA SOSTENIBILIDAD Y LA ACTIVIDAD ECONÓMICA}

Como hemos visto, la ampliación de la actividad museística a partir de 1980, con una tipología muy variada por aumento de la demanda de productos culturales y la ampliación del concepto de patrimonio, se ha traducido, entre otras cosas, en la creación de numerosos museos, lo que ha permitido recuperar múltiples edificios y construir otros de nueva planta para ese destino. Los museos contribuyen a la sostenibilidad medioambiental y a la calidad paisajística de las ciudades, y más aún de sus centros históricos, al conservar sus edificios y construir otros que se convierten en hitos, en elementos de referencia del paisaje, y todo en el contexto de un turismo en constante renovación, como la sociedad actual, que no cesa de desarrollar prácticas nuevas, entre ellas la frecuentación cada vez mayor de los museos y de los lugares de memoria histórica de los que los museos son, a menudo, la mejor expresión.
A veces, las formas innovadoras convierten los museos nuevos en elementos de atracción turística en sí mismos y de renovación del paisaje, al tiempo que contribuyen a revitalizar museos y colecciones ubicadas en sus inmediaciones pero que permanecieron ajenos durante décadas o en un segundo plano respecto al turismo de masas, como ha sucedido con el Museo Guggenheim de Bilbao respecto al de Bellas Artes, en una ubicación muy próxima. Este último, fundado en 1908 y con riquísimos fondos pictóricos, ha permanecido fuera del turismo de masas hasta su reforma y reapertura el 10 de noviembre de 2001, cuando el Guggenheim estaba ya en funcionamiento. En 2008, el Museo de Arte Contemporáneo Guggenheim recibió ya casi a un millón de visitantes, convertido en museo "estrella", el 66,7\% de los visitantes de los museos del País Vasco, y el de Bellas Artes, el 19,3\%, según las Estadísticas de Museos y Colecciones de Euskadi. Desde entonces sus cifras no dejan de aumentar hasta los 1.169.404 en 2016 , de los que el $66 \%$ son extranjeros, aunque 
con oscilaciones en función del atractivo de sus exposiciones temporales.

Por otra parte, la creciente afluencia del público a los museos hace que muchos sean sostenibles en términos económicos al obtener ingresos que garantizan su funcionamiento. De los museos de Euskadi, el $75,5 \%$ genera ingresos suficientes para su autofinanciación, y el restante $24,5 \%$, no, según el Departamento de Educación Cultura del País Vasco. Entre los que consiguen ingresos propios (tres de cada cuatro), un $82,9 \%$ procede de las entradas y el resto de otras ventas (tiendas propias, cesión de espacios, etc.). No obstante, al margen de este análisis, la sostenibilidad social queda siempre asegurada, porque todos los museos contribuyen no solo a conservar elementos patrimoniales sino a difundir el conocimiento, a reforzar sentimientos de identidad colectiva, territorialidad, respeto, solidaridad y comprensión del pasado y de otras culturas, objetivos contemplados a su vez por el turismo sostenible.

Los efectos positivos sobre la actividad económica y el desarrollo local se ponen también de manifiesto con casos como los vistos de Málaga y Cartagena, donde los museos se han convertido en los principales recursos de atracción turística, en la oferta más cuidada y elaborada con el apoyo de Planes locales de Estrategia Turística. En Málaga, el Ayuntamiento apuesta expresamente por un turismo cultural de calidad, alternativo al de sol, playa y golf, con el horizonte 2016-2020 y siempre con criterios de sostenibilidad. Todo esto responde además a la creciente demanda de productos culturales, a estrategias de diversificación estimuladas por el Plan Nacional de Desarrollo Integral del Turismo de España 2012-2015 y a objetivos del Consejo Internacional de Museos (ICOM) y la Federación Mundial de Amigos de los Museos (WFF) para el turismo cultural sostenible mundial.

Por último, los museos crean riqueza a través del empleo directo que generan, de la venta de productos culturales, de su complementariedad con otras ofertas de la misma naturaleza (teatro, exposiciones, conciertos, cine, etc.) y de la necesidad de infraestructuras de alojamientos y restauración. De ese modo, en torno a los museos proliferan restaurantes y bares, y a menudo se alcanzan las mayores densidades hoteleras, si bien esas infraestructuras se diseñan para el turismo en general, que en el caso de las ciudades es fundamentalmente cultural y de negocios. Así, en Madrid, el distrito Centro, en el que se ubican la mayoría de los museos, agrupa el mayor número de hoteles y ha duplicado sus plazas de alojamiento entre 1987 y 2016. La mayor densidad hotelera se registra entre el Paseo del Prado y la Plaza de España-Plaza de Oriente, a lo largo de las vías que lo atraviesan en sentido este-oeste, como la Gran Vía, Carrera de San Jerónimo y Atocha. En conexión con ese espacio, a lo largo de Recoletos y de la Castellana y calles colindantes se ubica otra zona hotelera que culmina en el entorno de la Plaza Castilla y Estación de Chamartín, y más distante, un tercer eje hotelero, desde la Castellana al aeropuerto de Barajas por las calles de María de Molina, Avenida de América y la Nacional II, en donde destaca el multicolor edificio postmoderno del Hotel Puerta de América en el que han intervenido tres premios Pritzker-el Nobel de la Arquitectura-Norman Foster, Zaha Hadid y Jean Nouvel. Cada una de sus doce plantas propone un diseño diferente de habitaciones y ha sido diseñada por un top de la arquitectura, incluido el aparcamiento.

En definitiva, los museos y salas de exposición constituyen una oferta consolidada dentro del turismo cultural, capaz de generar actividad económica y mejorar el paisaje, siempre desde principios de sostenibilidad contemplados en las Cumbre de la Tierra de 1992 y de Río + 21, en la Cumbre sobre Desarrollo Sostenible de 2015 en Nueva York, en la Nueva Agenda Urbana que resulta de la Conferencia de Naciones Unidas sobre la Vivienda y el Desarrollo Urbano Sostenible, de 2016, en la Carta del Turismo Sostenible de Lanzarote de 1995 y en la Cumbre sobre el Turismo Sostenible de 2015 en Vitoria-Gasteiz. A ello se une la aportación de la tarea fundamental de los museos: conservar la memoria del pasado, formar a la población y potenciar sentimientos de identidad colectiva, de pertenencia a los lugares y de respeto y tolerancia hacia otras culturas.

\section{AGRADECIMIENTOS}

Expresamos nuestro agradecimiento por las facilidades para la utilización de datos e información extraída del proyecto de investigación Dinámicas comparadas para una gestión sostenible de los paisajes culturales a través del turismo, concedido por el Ministerio de Ciencia e Innovación con referencia CS02011, y dirigido por M. Antonio Zárate Martín como investigador principal. 


\section{BIBLIOGRAFÍA}

Ballart Hernández, J. y Juan i Tresserras, J. (2008). Patrimonio y museos en el presente. En Ballart Hernández, J. y Juan i Tresserras, J. Gestión del patrimonio cultural. Madrid: Ariel, pp. 59-82.

Bellido Blanco, A. (2005). La renovación museológica en España durante los años setenta. Museo, 10, pp. 1-17.

Bolaños, M. (1997). Museos bajo el franquismo. En Bolaños, M. Historia de los museos en España. Gijón: Trea.

Bono, F. (2016, 25 de noviembre). Norman Foster remata la ampliación del Prado con una gran zona peatonal. El País. Disponible en: https://elpais. com/cultura/2016/11/24/actualidad/1479984145_065475.html

Cañas, G. (1986, 1 de agosto). El primer presupuesto del Museo del Prado como organismo autónomo supera en 1.000 millones al de este año. El País. Disponible en: https://elpais.com/diario/1986/08/01/cultura/523231203_850215.html

Chinchilla Gómez, M. (2005). Una mirada profesional sobre la creación de museos. Museos.es. Revista de la Subdirección General de Museos Estatales, 1, pp. 48-59.

Equipe M.I.T. (2002). Tourismes 1, Lieux communs. Paris: Belin.

Fernández Fúster, L. (1991). La Segunda Guerra Mundial. Los terribles años cuarenta. En Fernández Fúster, L. Historia general del turismo de masas. Madrid: Alianza Editorial, pp. 327-515.

Fernández Sabau, M. (2009-2010). ¿Planificación sostenible? Una panorámica de la planificación actual de museos en España. Museos.es Revista de la Subdirección General de Museos Estatales, 5-6, pp. 38-49.

García Ferrero, A. (2016). Ocio y turismo en el pasiaje madrileño [Tesis doctoral inédita].
Madrid: Universidad Nacional de Educación a Distancia.

García Pérez, M. C. et al. (2003a). Casco histórico. En Berlinches (dir.) y Barreiro Pereira, P. (coord.) Arquitectura de Madrid (vol. 1). Madrid: Fundación Cultural COAM.

García Pérez, M. C. et al. (2003b). Ensanches. En Berlinches, A. (dir.) y Barreiro Pereira, P. (coord.) Arquitectura de Madrid (vol. 2). Madrid: Fundación Cultural COAM.

Garrett, B. (2012). Undertaking recreational trespass: urban exploration and infiltration. Transactions of the Institute of British Geographers, 39 (1), pp. 1-13. https://doi.org/10.1111/tran.12001

Gavira, C. (1981). La configuración del eje Prado-Recoletos-Castellana (1630-1975). Anales del Instituto de Estudios Madrileños, XVIII, pp. 221-250.

Michel, F. (2012). L'ailleurs chez soi : tourisme de proximité et exotisme à domicile. L'Autre Voie, 8, pp. 1-8.

Montaner Martorell, J. M. (2005). La renovación arquitectónica de los museos de Madrid. Museos.es. Revista de la Subdirección General de Museos Estatales, 1, pp. 113-121.

Morales, F. J. (2016). La puesta en valor del paisaje y el patrimonio como propuesta para el desarrollo local. En Zárate Martín, M. A. (dir.) Paisajes culturales a través de casos en España y América. Madrid: UNED.

Nieto Gallo, G. (1973a). Situación de los museos españoles. En Nieto Gallo, G. Panorama de los museos españoles y cuestiones museológicas. Madrid: Asociación Nacional de Bibliotecarios, Archiveros y Arqueólogos, pp. 23-38.

Nieto Gallo, G. (1973b). Apéndices. En Nieto Gallo, G. Panorama de los museos españoles y cuestiones museológicas. Madrid: Asociación Nacional de Bibliotecarios. Archiveros y Arqueólogos, pp. 101-195.
Pardo Abad, C. J. (2004). Vaciado industrial de la ciudad. En Pardo Abad, C. J. Vaciado industrial y nuevo paisaje urbano en Madrid. Antiguas fábricas y renovación de la ciudad. Madrid: La Librería, pp. 69-122.

Rodríguez Ariza, M. (2008). Una arquitectura tradicional de tipo urbano: la corrala. En Rodríguez Ariza, M. Arquitectura tradicional en la Comunidad de Madrid. Llegar a tiempo... Madrid: La Librería, pp. $175-180$

Vergopoulos, H. (2013). Être touriste chez soi. Le tourisme comme modèle socioculturel d'appropriation du territoire quotidien. En François, H., Bourdeau, P. y Perrin-Bensahe, L. (dirs.). Fin (?) et confins du tourisme. Interroger le statut et les pratiques de la récréation contemporaine. Paris: L'Harmattan, pp. 53-62.

Zárate Martín, M. A. (2011). La visita de empresa, otra forma de hacer turismo. Estudios Geográficos, 72 (270), pp. 291-321. https://doi.org/10.3989/estgeogr.201112

Zárate Martín, M. A. (2016). Paisajes culturales urbanos, oportunidad para la conservación del patrimonio y el turismo sostenible. Estudios Geográficos, 77 (281), pp. 693-728. https://doi. org/10.3989/estgeogr.201624

\section{Otros recursos}

Museo del Prado. Enciclopedia. Cronología del Museo. [En línea]. [Fecha de consulta: 15 agosto 2015]. Disponible en: https://www.museodelprado.es/enciclopedia/cronologia-del-museo/.

Rath, J. (2007). The transformation of Ethnic Neighborhoods into Places of Leisure and Consumption. Institute for Migration and Ethnic Studies (IMES) / University of Amsterdam. Working paper 144. Disponible en https://ccis.ucsd.edu/_files/wp144.pdf 